\title{
Regulation of ocular blood flow during increases of arterial blood pressure
}

\author{
Georg Michelson, Martina Groh, Anselm Gründler
}

\begin{abstract}
The blood flow in the uvea in cats and monkeys during acute increases of arterial blood pressure is well controlled by a sympathetic mechanism protecting the eye from overperfusion. Ocular macrocirculation (ophthalmic artery) and ocular microcirculation (iris) were examined in 22 healthy subjects during acute increases of arterial blood pressure induced by physical exercise $(125 \mathrm{~W})$. With a data aquisition and storage software in real time mode several parameters of ocular perfusion and systemic functions were measured simultaneously. Blood flow parameters were measured in the ophthalmic artery by pulsed Doppler sonography and in the iris by laser Doppler flowmetry. Systolic, diastolic, and mean velocities of the ophthalmic artery peak velocity pulse curve, the ophthalmic artery mean velocity pulse curve, and the iris velocity pulse curve were estimated off line. The ophthalmic artery mean velocity pulse curve resembles the integrated velocity of all erythrocytes in the vessel including the slowly running cells near the vessel wall. The iris velocity pulse curve was calculated by a special statistic procedure (ALDF). After exercise there was a significant increase in systolic and diastolic blood pressure and heart rate. The pulse curve of the ophthalmic artery showed significantly increased systolic and decreased diastolic velocities. The vascular resistance of the branches of the ophthalmic artery increased significantly. The iridal vasculature showed no significant change in blood cell velocity but an increased vascular resistance. It was observed that the elevated perfusion pressure was associated with an increased vascular resistance and a constant mean blood velocity in the ophthalmic artery and iridal vessels. The parallel elevation of vascular resistance and blood pressure during exercise may be the reason for a constant blood flow in the ophthalmic artery and the iris. This may be accounted for by a sympathetic mechanism for protecting the eye from overperfusion.

(Brf Ophthalmol 1994; 78: 461-465)
\end{abstract}

Several authors observed in rabbits, cats, and monkeys, a good regulation of the ocular blood flow during increased perfusion pressures. In these observations sympathetic stimulation reduced the blood flow in all parts of the uvea in these animals. The physiological role of the sympathetic nerves in ocular blood flow control may be to maintain the blood flow at a suitable level under conditions of sudden increases in arterial blood pressure. Such increases tend to cause an overperfusion of the eye resulting in a breakdown of the blood-aqueous barrier. ${ }^{123}$

The aim of this study was to investigate the control of blood flow in the ophthalmic artery (macrocirculation) and in the iris (microcirculation) during acute increases of arterial blood pressure in humans. The blood flow in the ophthalmic artery was measured by pulsed Doppler sonography, the blood flow in the iris by laser Doppler flowmetry.

\section{Method}

The arterial blood pressure was increased by exercise. Twenty two healthy volunteers (mean age 45.0 (SD 13.1) years) climbed five floors in $60-120$ seconds $(125 \mathrm{~W})$. Before and directly after exercise over a period of 15 minutes the blood flow in the ophthalmic artery and systemic factors were simultaneously and continuously measured and stored. In 10 of the volunteers (mean age $31.4(9.2)$ years) the blood flow in the iridal vasculature additionally was measured simultaneously before and after exercise over a period of 15 minutes. All examinations were performed in the supine position.

With a data acquisition and storage software (maximally 16 channels) several parameters of ocular perfusion and systemic functions were measured simultaneously in real time mode ophthalmic artery blood velocity, iris blood flow, cardiac pulse, respiration, and arterial blood pressure. The cardiac pulse and respiration were measured continuously (Sirecust 720 , Siemens, Germany). The arterial blood pressure was examined by oscillometric methods at 2 minute intervals (Sirecust 888, Siemens, Germany). The blood velocity in the ophthalmic artery was measured by pulsed Doppler sonography (Trancraniell Doppler, EME, Germany, $4 \mathrm{MHz}$ transducer). Systolic, diastolic, and mean velocities of the peak velocity pulse curve and mean velocity pulse curve were determined off line. The peak velocity pulse curve resembles the velocity of the fastest erythrocytes in the centre of the ophthalmic artery. The mean velocity pulse curve is the integrated velocity of all erythrocytes in the vessel including the slowly running cells near the vessel wall. Thus, the 
mean velocity pulse curve is at any time of lower velocity than the peak velocity pulse curve and proportional to the volume blood flow in the ophthalmic artery. This is true under the assumption of a constant diameter of the ophthalmic artery and constant blood viscosity during the measurement. With the direction of insonation from the upper lid to the foramen opticum and an orbital measuring depth of 39 (4) $\mathrm{mm}$ the identification of the ophthalmic artery was achieved. After visual and acoustic optimisation of the pulse curve (monitor and headphones) by varying the angle with the handheld transducer, the pulse curves were stored. The arithmetic means of the systolic, diastolic, and mean velocity are used for further data processing. The measured blood velocity, $v^{\star}$, is related to the real velocity, $v$, by the cosine of the angle, $a$, between the axis of the ultrasound beam and the vessel. Owing to this function the trigonometric velocity error (TVE) depends on the angle a: TVE $(\%)=(1-$ cosine $a) \times 100$ with TVE $(\%)=(v-$ $\left.\mathrm{v}^{\star}\right) \times 100 / \mathrm{v}$ and $\mathrm{v}^{\star}=\mathrm{v}$ cosine $\mathrm{a}$. Within an insonation angle a of $40^{\circ}\left(-20^{\circ}\right.$ to $\left.+20^{\circ}\right)$, the TVE is therefore maximally $8 \%$. All further data are based on the measured velocity, $v^{\star}$.

The iris blood flow was measured by laser Doppler flowmetry (BPM 403A, wavelength $780 \mathrm{~nm}$, power $<1.6 \mathrm{~mW}$, TSI, USA). The procedure is based on measurements of frequency shifts of the reflected laser light scattered back by moving cells. ${ }^{6}$ In our set up laser light was projected by a fibre optic transcorneally onto the iris illuminating an area of about $1 \mathrm{~mm}^{2}$. By laser Doppler flowmetry only small vessels and capillaries were measured because of a cut of frequency shifts higher than $20 \mathrm{kHz}$. The laser Doppler measurements were performed in a room illuminated by constant neon light (about 500 foot candles). All examinations were performed in supine position with the volunteers looking at a fixation point on the ceiling. All pupils showed normal light reactivity, having no influence on the laser Doppler measurement of

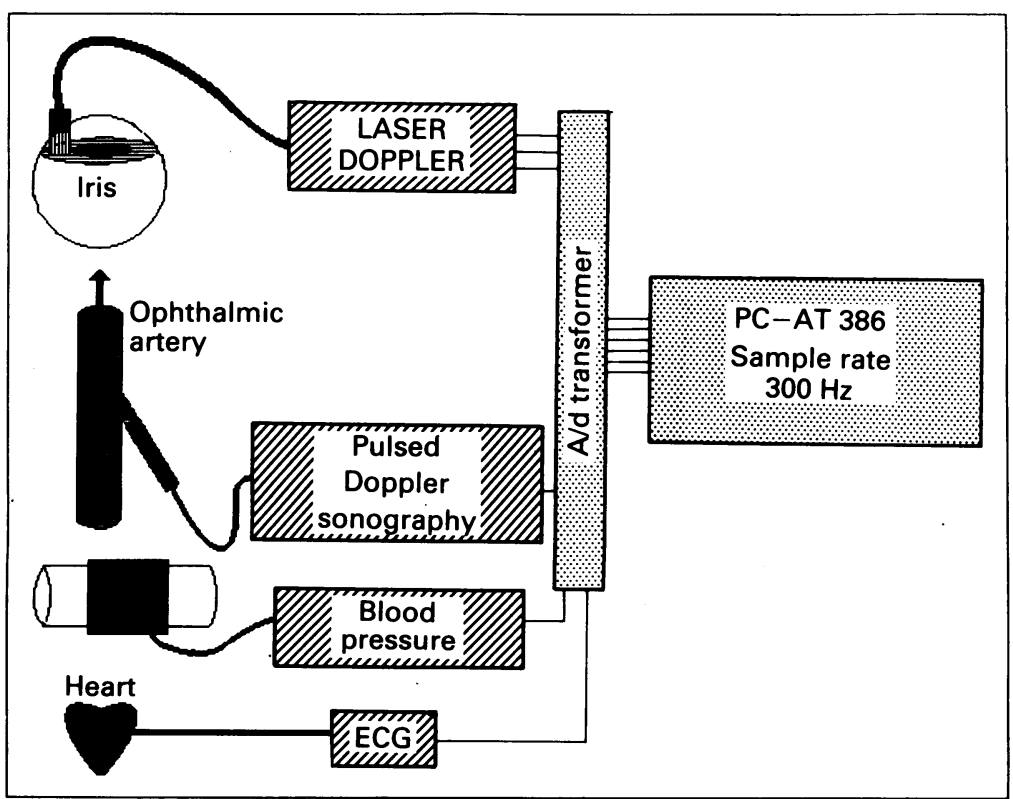

Figure 1 Scheme of experimental set up. Note the simultaneous measurement of ocular macrocirculation by Doppler sonography and microcirculation by laser Doppler flowmetry, and systemic factors. the iris. The measurements of iridal blood flow were performed simultaneously with the examination of the ophthalmic artery blood velocity. The laser probe was held in the right hand and the ultrasound transducer was held in the left hand. In one volunteer the IOP was measured by the pneumotonometry method ('Langham' probe) simultaneously with the examination of iridal and ophthalmic artery blood flow.

Figure 1 shows the recording set up.

\section{CONCEPT OF SIGNAL PROCESSING IN LASER} DOPPLER FLOWMETRY

The laser light illuminates via fibre optics a volume of tissue which contains both red cells and stationary tissue cells. Laser light is randomly scattered by both cell types. Light scattered by moving cells shows a mixture of frequencies due to the Doppler principle ('frequency shift'); in contrast, light scattered only by stationary cells show no frequency shift ('no frequency shift'). The scattered light is collected by a return fibre which is coupled to a photodetector. The electrical signal from the photodetector contains frequency and voltage information. The DC offset is the average voltage generated by all photons (frequency shifted and non-frequency shifted) returned to the photodetector at any given time. The AC signal is the root mean square (RMS) voltage of the fluctuating signal. By performing an autocorrelation on the electrical signal the mean frequency $f$ is determined which is proportional to the average velocity of the moving red cells ('velocity'). The ratio of $\mathrm{AC}$ and $\mathrm{DC}$ photodetector voltage leads to an index proportional to the blood volume in the sample volume ('volume'). By this algorithm two independent outputs are produced continuously: (1) 'volume' which is proportional to the blood volume in the sample volume (without unit), and (2) 'velocity' which is proportional to the mean blood velocity in the sample volume (in $\mathrm{kHz}$ ). The capillary blood flow is calculated by the equation 'flow'= volume $\times$ velocity (in arbitrary units [flux]). ${ }^{789}$

AVERAGING LASER DOPPLER FLOWMETRY

For improvement of the signal to noise ratio statistical averaging was performed. By averaging 100 sweeps of 2 second length of the signals volume, velocity, and flow triggered by the $R$ onset of the ECG only fluctuations synchronous with the ECG remain since all others are filtered out. With this method stable and reproducible iridal pulse curves of blood flow were established with systolic maximum and diastolic minimum. Fluctuations in iridal blood flow caused by respiration, vasomotion, or eye movements were eliminated. Only ECG/arterial blood pressure associated changes of capillary blood flow become visible. ${ }^{10}$ In the following this statistical procedure is called 'averaging laser Doppler flowmetry' (ALDF). The intrasubject variance of two pulse curves measured within 1 hour by one examiner is for volume $5 \cdot 1 \%$, for velocity $6 \cdot 1 \%$, and for flow $7 \cdot 9 \%$. In Figure 2 are demonstrated the simultaneously measured iridal pulse curves of volume, velocity, flow and 


\section{Averaged data (100 sweeps)}

Example 1

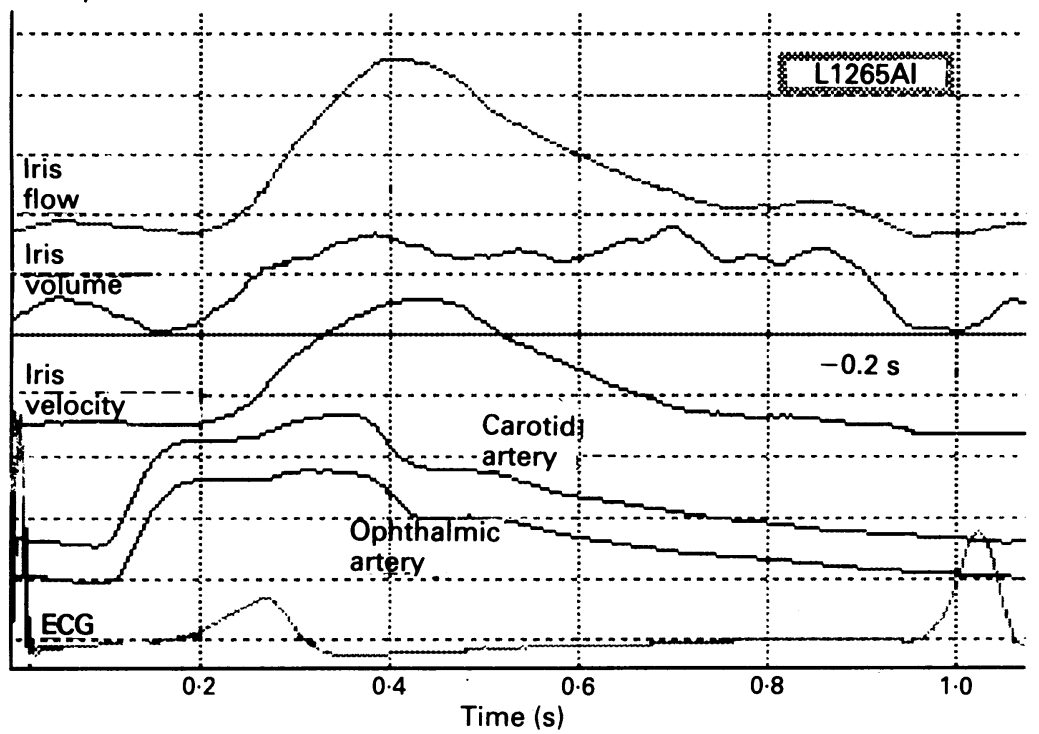

Figure 2 Amplified iridal pulse curves of flow, volume, and velocity of a healthy young person processed by ALDF. Note simultaneously measured pulse curves of ophthalmic and internal carotid artery blood velocity with different time intervals from the cardiac action and the pulse curves. The pulse curve of the internal carotid is shown for better understanding.

Figure 3 Diastolic and systolic arterial blood pressure with the arithmetic mean $(n=22)$ and $1 S D$ as $a$ function of time. $0=$ before exercise, $1-8=$ number of minutes after exercise.

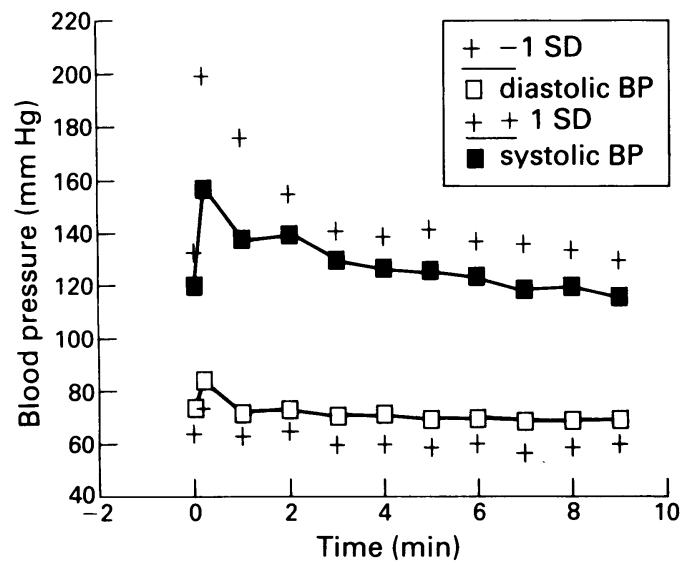

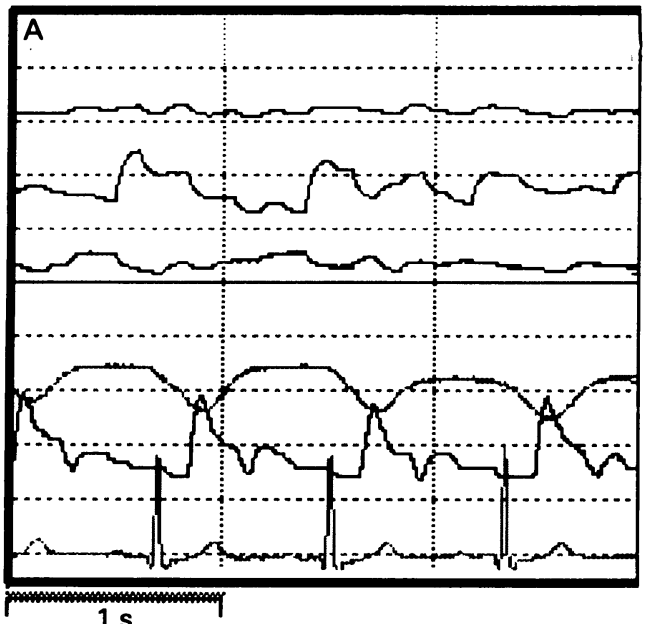

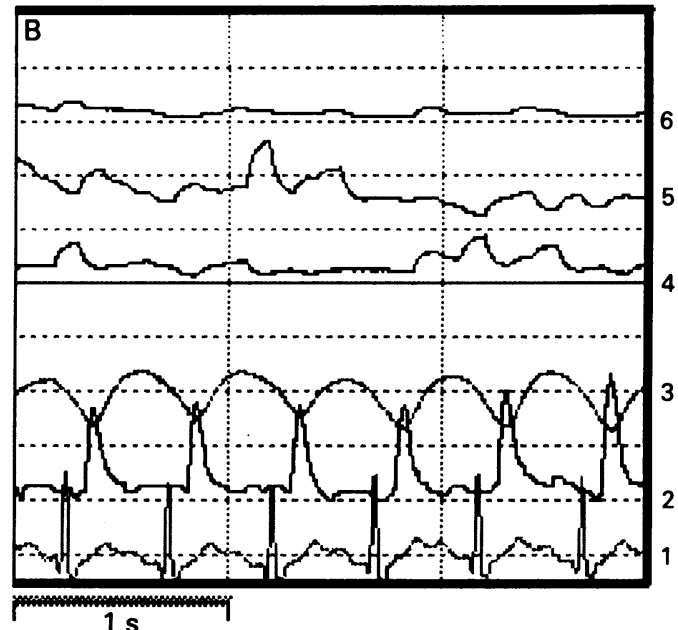

STATISTICS

The level of significance was determined by the Mann-Whitney-Wilcoxon test (SPSS). The test used is a non-parametric test and does not require a normally distributed population.

The laser light using an energy lower than 1.6 $\mathrm{mW}$ (laser class I) had no effect on the tissue. Informed consent was obtained from all volunteers.

Figure 4 Ophthalmic artery and iris blood flow combined with intraocular pressure pulse curve $(a)$ before and $(b)$ just after physical exercise in a young healthy volunteer. 
Figure 5 Systolic and diastolic velocity of the peak velocity pulse curve of the ophthalmic artery with the arithmetic mean $(n=22)$ and I SD as a function of time. $0=$ before exercise, $1-8=$ number of minutes after exercise.

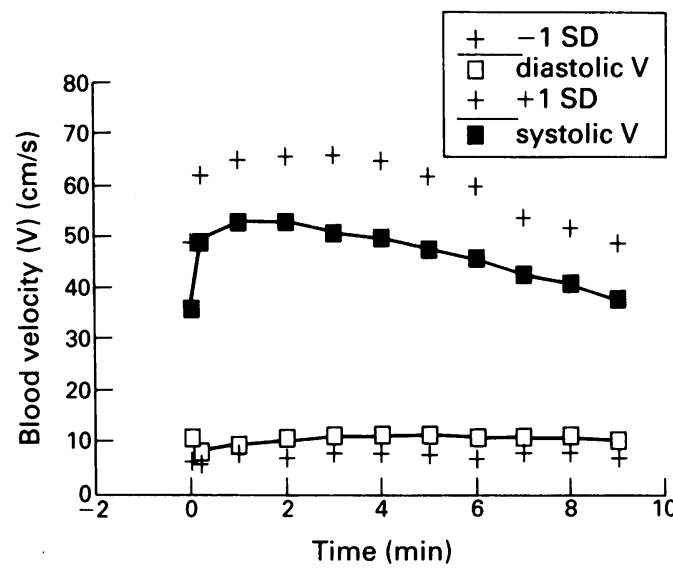

Figure 6 Mean of mean velocity pulse curve of the ophthalmic artery with the arithmetic mean $(n=22)$ and $1 S D$ as an index for volume blood flow in the ophthalmic artery as a function of time. $0=$ before exercise, $1-8=$ number of minutes after exercise.

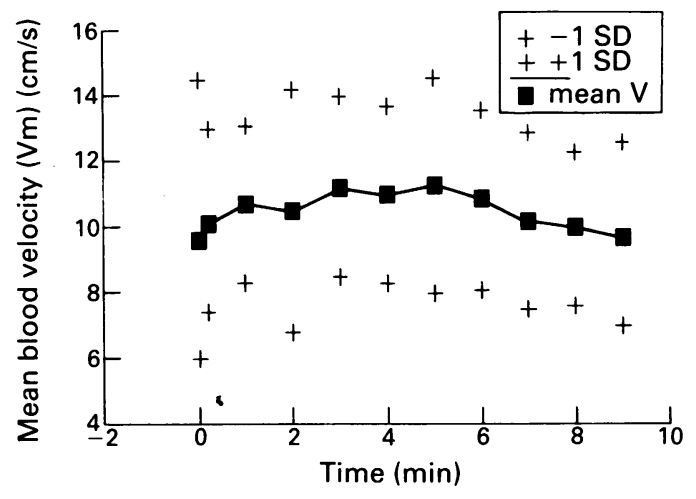

\section{Results}

ARTERIAL BLOOD PRESSURE

After exercise there was a significant increase in systolic and diastolic arterial blood pressure (sBP 120 (13) to 157 (42) $\mathrm{mm} \mathrm{Hg}, \mathrm{dBP} 74$ (10) to 84 (10) $\mathrm{mm} \mathrm{Hg}$ ). Figure 3 shows the time course of the arterial blood pressure before and after exercise.

OPHTHALMIC ARTERY

Figure 4 shows as an example the blood flow data before and after exercise of the ophthalmic artery

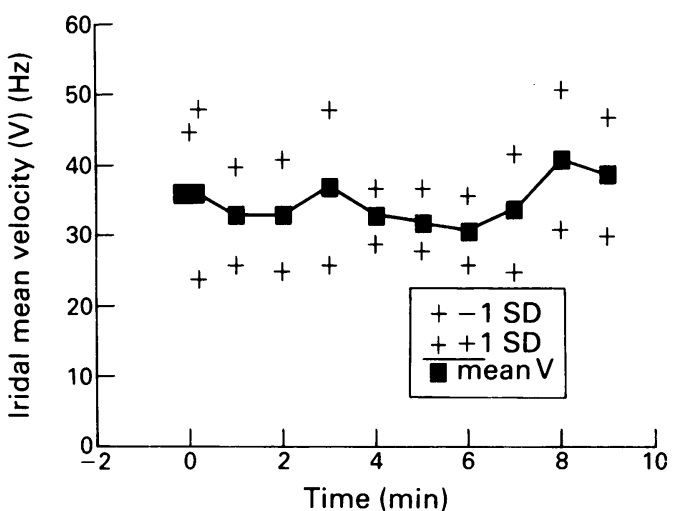

Figure 7 Mean velocity of iris with the arithmetic mean $(n=$ 10 ) and $1 S D$ as a function of time. Note $0=$ before exercise, $1-8=$ number of minutes after exercise.

and of the iris combined with the intraocular pressure of a young healthy subject. After exercise there was on average a significant increase in the systolic peak velocity $(36(13)$ to $53(13) \mathrm{cm} / \mathrm{s}$ ) and on average a significant decrease in the diastolic peak velocity $(10$ (4) to $8(2) \mathrm{cm} / \mathrm{s}$ ) (Fig 5). The vascular pulsatility index RIO of the ophthalmic artery increased significantly just after exercise (RIO $0.69(0.05)$ to 0.83 $(0.04), \mathrm{p}<0.001)$ and returned slowly to normal values after $8-10$ minutes. The time course of the mean of the mean velocity pulse curve as an index for volume blood flow in the ophthalmic artery showed no significant change (Fig 6). Table 1 summarises the data of the ophthalmic artery blood flow and systemic factors.

\section{IRIS PERFUSION}

Our data showed no significant increase in iridal blood flow parameters immediately after exercise (velocity $0.037(0.009)$ to $0.041(0-01) \mathrm{kHz}$, volume $0.21(0.06)$ to $0.24(0.06)$ ) (Fig 7). The iris vascular pulsatility index RII (Pourcelot index) increased significantly after exercise $(0 \cdot 11$ $(0.14)$ to $0.22(0.07), \mathrm{p}<0.03)$. Table 2 summarises the parameters of iridal blood flow and systemic factors before and just after exercise.

Table 1 Ophthalmic artery blood velocity and systemic factors before and after acute exercise (125 W), $n=22$

\begin{tabular}{|c|c|c|c|c|c|c|c|c|}
\hline & $\begin{array}{l}s B P \\
(m m H g)\end{array}$ & $\begin{array}{l}d B P \\
(m m H g)\end{array}$ & $\begin{array}{l}m B P \\
(m m H g)\end{array}$ & $\begin{array}{l}H R \\
\text { (beats/min) }\end{array}$ & $\begin{array}{l}s P V \\
(\mathrm{~cm} / \mathrm{s})\end{array}$ & $\begin{array}{l}d P V \\
(\mathrm{~cm} / \mathrm{s})\end{array}$ & $\begin{array}{l}\text { Mean } \\
M V \\
(\mathrm{~cm} / \mathrm{s})\end{array}$ & $R I O$ \\
\hline $\begin{array}{l}\text { Before exercise (SD) } \\
\text { Just after exercise (SD) } \\
\text { Level of significance }\end{array}$ & $\begin{array}{l}120(13) \\
157(42) \\
\star \star\end{array}$ & $\begin{array}{l}74(10) \\
84(10) \\
\star \star\end{array}$ & $\begin{array}{l}85(25) \\
108(12)\end{array}$ & $\begin{array}{l}67(11) \\
103(25) \\
\star \star\end{array}$ & $\begin{array}{l}36(13) \\
53(13) \\
\star \star\end{array}$ & $\begin{array}{l}10(4) \\
8(2)\end{array}$ & $\begin{array}{l}9(3) \\
10(3) \\
\text { NS }\end{array}$ & $\begin{array}{l}0.69(0.05) \\
0.83(0.04) \\
\star \star\end{array}$ \\
\hline
\end{tabular}

${ }^{\star} \mathrm{p}<0.01,{ }^{\star} \mathrm{p}<0.001$, Mann-Whitney-Wilcoxon test.

$\mathrm{sBP}=$ systolic blood pressure, $\mathrm{dBP}=$ diastolic blood pressure, $\mathrm{mBP}=$ mean blood pressure, $\mathrm{HR}=$ heart rate, $\mathrm{sPV}=$ systolic peak velocity ophthalmic artery, $\mathrm{dPV}=$ diastolic peak velocity ophthalmic artery, mean $M V=$ mean of mean velocity pulse curve ophthalmic artery, $\mathrm{RIO}=$ ophthalmic artery pulsatility index $[\mathrm{RIO}=(\mathrm{sPV}-\mathrm{dPV}) / \mathrm{sPV}]$.

Table 2 Iridal blood flow and systemic factors before and after acute exercise (125 W), $n=10$

\begin{tabular}{|c|c|c|c|c|c|c|c|c|}
\hline & $\begin{array}{l}s B P \\
(m m H g)\end{array}$ & $\begin{array}{l}d B P \\
(m m H g)\end{array}$ & $\begin{array}{l}\text { HR } \\
\text { (beats/min) }\end{array}$ & $\begin{array}{l}\text { sysVel } \\
(\mathrm{kHz})\end{array}$ & $\begin{array}{l}\operatorname{diaVel} \\
(\mathrm{kHz})\end{array}$ & $m V o l$ & $\begin{array}{l}\text { mFlow } \\
(\text { Flux })\end{array}$ & $R I I$ \\
\hline $\begin{array}{l}\text { Before exercise (SD) } \\
\text { Just after exercise (SD) } \\
\text { Level of significance } \\
\text { (p) }\end{array}$ & $\begin{array}{l}118(11) \\
150(14) \\
0.001 \\
\star \star\end{array}$ & $\begin{array}{l}72(8) \\
79(9) \\
0 \cdot 15 \\
\text { NS }\end{array}$ & $\begin{array}{c}71(11) \\
101(32) \\
0.03\end{array}$ & $\begin{array}{l}0.0377(0.009) \\
0.0414(0.013) \\
0.53 \\
\text { NS }\end{array}$ & $\begin{array}{l}0.0333(0.009) \\
0.0318(0.010) \\
0.82 \\
\text { NS }\end{array}$ & $\begin{array}{l}0.213(0.069) \\
0.248(0.066) \\
0.2 \\
\text { NS }\end{array}$ & $\begin{array}{l}6 \cdot 2(1 \cdot 7) \\
7 \cdot 9(1 \cdot 8) \\
0 \cdot 07 \\
\text { NS }\end{array}$ & $\begin{array}{l}0.11(0.14) \\
0.22(0.07) \\
0.03 \\
\star\end{array}$ \\
\hline
\end{tabular}

${ }^{\star} \mathrm{p}<0.05,{ }^{\star \star} \mathrm{p}<0.001$, Mann-Whitney-Wilcoxon test.

$\mathrm{sBP}=$ systolic blood pressure, $\mathrm{dBP}=$ diastolic blood pressure, $\mathrm{HR}=$ heart rate, sysVel=systolic velocity iris, diaVel=diastolic velocity iris, $m$ Vol = mean volume iris, $m F l o w=$ mean flow iris, $R I I=$ vascular pulsatility index [RII $=($ sysVel-diaVel $) /$ sysVel] . 


\section{Discussion}

The estimation of the vascular resistance by the shape of the pulse curve according to Pourcelot is commonly used in Doppler sonography, especially in transcranial Doppler sonography (equation (1)). ${ }^{12}$ The Pourcelot index is based on empirical and experimental studies. Legarth and Nolsoe have shown (in measurements on the brachial artery by Doppler sonography) that there is a positive relation between the vascular resistance and the Pourcelot index. ${ }^{13}$

Thus, the vascular resistance in the ophthalmic artery is expressed by RIO (RI Ophthalmic artery). Physical exercise increases the arterial blood pressure by stimulating the sympathetic nervous system and by releasing adrenergic transmitters producing also vasoconstriction with elevation of vascular resistance. It has been observed in previous studies in experimental animals that an acute increase in blood pressure tends to cause overperfusion with blood in the eye, and that such overperfusion can be prevented if the sympathetic nerves to the eye are stimulated. The orbital sympathetic nerves originating from the superior cervical ganglion innervate all uveal vascular beds. ${ }^{14} \mathrm{Alm}$ and Bill observed in rabbits, cats, and monkeys a sympathetic mechanism which protects the eye from overperfusion. ${ }^{123} \mathrm{Alm}$ et al measured iridal blood flow by labelled microspheres in monkeys at different perfusion pressures and found almost constant blood flow in the iridal vasculature. ${ }^{15}$ Ernest showed in monkeys that arterial hypertension and ocular sympathectomy produce an overwhelming fluorescein leakage from the choroidal circulation owing to lack of the compensatory sympathetic vasoconstriction. ${ }^{16}$

In this paper we have not examined the effect of exercise on intraocular pressure. Harris et al have shown that exercise shows no major effect on IOP. ${ }^{17}$

\section{OPHTHALMIC ARTERY}

We observed increased systolic, decreased diastolic velocities, and increased vascular pulsatility indices in the ophthalmic artery just after exercise. The observed data account for a regulation of blood flow during increased arterial blood pressure by a sympathetic induced increase of vascular resistance. Elevation of perfusion pressure (on average $+22 \%$ ) was associated with an increased vascular resistance (on average $+20.8 \%$ ) in the branches of the ophthalmic artery. This may be the cause of the observed constant mean blood velocity in the ophthalmic artery indicating constant volume blood flow in the ophthalmic artery. The mean blood velocity of the mean velocity pulse curve. is proportional to the mean volume blood flow in the ophthalmic artery under the assumption of constant diameter of the ophthalmic artery and constant blood viscosity.

IRIS

After exercise we observed a significant increase in arterial blood pressure, a constant iridal blood flow, and a significant elevated vascular pulsatility index of the iridal vasculature. The data suggest that an acute increase in arterial blood pressure caused by physiological exercise leads to an elevation of vascular resistance with nearly constant iridal blood flow parameters. The mean iridal blood cell velocity $(\mathrm{mVel})$ as a function of mean arterial blood pressure (mBP) shows mainly constant values at different values of mean arterial blood pressure. The constant $\mathrm{mVel}$, while the mean arterial blood pressure ranged from 75 to $130 \mathrm{~mm} \mathrm{Hg}$, signifies sufficient blood flow regulation during physiological exercise.

The increased sympathetic level during exercise leads to a vasoconstriction of all orbital and ocular vessels. It is reasonable that during and shortly after exercise there is an elevation of vascular resistance by vasoconstriction of the branches of the ophthalmic artery. Overall these data suggest a sympathetic mechanism of regulation of blood flow in ocular vasculature in humans protecting the eye from overperfusion.

Supported by Deutsche Forschungsgemeinschaft Mi 320/2-2, Na 55/6-1

1 Alm A. The effect of sympathetic stimulation on blood flow through the uvea, retina, and optic nerve in monkeys. Exp Eye Res 1977; 25: 19-25.

$2 \mathrm{Alm} A$, Bill $\mathrm{A}$. The effect of stimulation of the sympathetic chain on retinal oxygen tension and uveal, retinal and cerebral blood flow in cats. Acta Physiol Scand 1973; 88. 84-96.

3 Bill A, Linder M, Linder J. The protective role of ocular sympathetic vasomotor nerves in acute arterial hypertensympathetic vasomotor nerves in acute arterial hyperten-
sion. In: Proceedings of the Ninth European Conference on Microcirculation, Antwerpen, Belgium, 1976. Bibl Anat 1977; 16: $30-7$.

4 Steinmeier R, Fahlbusch R, Powers A, Dötterl A, Buchfelder $M$. Pituitary microcirculation. Physiological aspects and clinical implications: a laser Doppler study during transsphenoidal adenomectomy. Neurosurgery 1991; 29: 47-54.

5 Michelson G, Gierth K, Priem R, Laumer R. Blood velocity in the ophthalmic artery in normal subjects and patients with endophthalmitis. Invest Ophthalmol Vis Sci 1990; 31: 1919-23.

6 Doppler C. Über das farbige Licht der Dopplersterne und einiger anderer Gestirne des Himmels. Abhandl Königl Böhm Ges Wiss 1843; Ser 2: 465-82.

7 Bonner R, Nossal R. Model for laser Doppler measurements of blood flow in tissue. Appl Optics 1981; 20: 2097-107.

8 Bonner R, Clem TR, Bowen PD, Bowman RL. Laser Doppler continuous real time monitor of pulsatile and mean blood continuous real time monitor of pulsatile and mean blood
flow in tissue microcirculation. In: Chen SH, Chu B, Nossal flow in tissue microcirculation. In: Chen SH, Chu B, Nossal $\mathbf{R}$, eds. Scattering techniques applied to supramolecula
equilibrium systems. New York: Plenum, 1981: 73-92.

9 Borgos JA. TSIs blood flowmeter. In: Shepard AP, Ödberg PA, eds. Laser Doppler flowmetry. Boston: Kluwer, 1990: 73-92.

10 Bill A. Circulation of the eye. In: Renkin EM, Michel CC, eds. Handbook of physiology. The cardiovascular system, microcirculation. Vol IV, Part 2. Bethesda, MD: American Physiological Society, 1984: 1001-34.

11 Pourcelot L. Applications cliniques de l'examen Doppler transcutane. Coloques de l'Institut Nationale de la Sante et de ta Recherche Medicale 1974; 34: 213-40.

12 Aaslid R. Cerebral hemodynamics. In: Newell DW, Aastid R, eds. Transcranial Doppler. New York: Raven Press, 1992: eds. Tr-55.

13 Legarth J, Nolsoe C. Doppler blood velocity waveforms and the relation to peripherial resistance in the brachial artery. f Ultrasound Med 1990; 9: 449-53.

14 Ehinger B. Adrenergic nerves to the eye and related structures in man and the cynomolgus monkey. Invest Ophthalmol $1966 ; 5: 42-8$

$15 \operatorname{Alm} A$, Bill A. Ocular and optic nerve blood flow at normal and increased intraocular pressures in monkeys (Macaca irus): a study with radioactively labelled microspheres including flow determinations in brain and some other tissues. Exp Eye Res 1973; 15: 15-29.

16 Ernest JT. The effect of systolic hypertension on rhesus monkey eyes after ocular sympathectomy. Am 7 Ophthalmol 1977; 84: 341-4.

17 Harris A, Malinovsky VE, Contor LB, Henderson PA, Martin $B J$. Isocapnia blocks exercise induced reductions in ocular tension. Invest Ophthalmol Vis $S_{c i}$ 1992; 33: 2229-32. 